\title{
TIPO DE PORTA-ENXERTO E ANELAMENTO DE RAMOS NO PEGAMENTO DA ENXERTIA EM LICHIEIRA (Litchi chinensis SONN.) ${ }^{1}$
}

\author{
ANTONIO BALDO GERALDO MARTINS ${ }^{2}$, ROBSON ANTONIO RAMOS ${ }^{3}$ E ANA VERUSKA CRUZDA SILVA ${ }^{4}$
}

\begin{abstract}
RESUMO - O presente trabalho foi realizado em condições de ripado, com o objetivo de avaliar o desempenho da enxertia a inglês simples, em dois tipos de porta-enxerto (pé-franco e alporquia), em combinação com três tipos de anelamento do ramo (sem anelamento, e ramos anelados duas e quatro semanas antes da retirada do garfo), em lichia. O experimento foi conduzido em delineamento inteiramente casualizado, com seis tratamentos e três repetições. Foi somente observada diferença significativa para o tipo pé-franco, que revelou os melhores resultados.
\end{abstract}

Termos para indexação: lichia, propagação, enxertia

\section{EVALUATION OF THE PERFORMANCE OF GRAFTING IN DIFFERENT ROOTSTOCKS AND GIRDLING OF LITCHI (Litchi chinensis SONN.)}

\begin{abstract}
This research work was carried out in the experimental area to evaluate the performance of grafting technique in two types of rootstocks (air layering and seedling) with three types of girdling (without girdling and girdling shoot, two and four weeks before grafts retreat) in litchi. The experimental design was a complete randomized with six treatments and three replications. There was statistical difference for the type of rootstocks that showed better results.
\end{abstract}

Index of terms: litchi, propagation, grafting

\section{INTRODUÇÃO}

Comercialmente, a lichieira é propagada por processo vegetativo, sendo o mais utilizado a alporquia, podendo-se também utilizar métodos como enxertia e estaquia. Também esta planta pode ser propagada por sementes e esta propagação via sexual confere às plantas uma alta variabilidade genética, embora a lichieira apresente um longo período juvenil (levando de dez ou mais anos) para produzir sementes.

Assim, a propagação vegetativa apresenta-se como uma alternativa para a reprodução. Entretanto, é pouco utilizada na lichia devido às baixas porcentagens de pegamento. Para obterse um aumento do pegamento, na enxertia, utiliza-se da aplicação de técnicas simples como, por exemplo, o anelamento do ramo algumas semanas antes da enxertia. Na lichieira, apesar de a alporquia ser mais utilizada, este método possui algumas desvantagens, entre elas o depauperamento da planta-matriz quando se obtém um grande número de mudas, além do método ser de execução bastante trabalhosa, restringindo e onerando a produção de mudas.

O presente trabalho teve por objetivo avaliar o comportamento entre dois tipos de porta-enxertos (pé-franco e alporque) e três épocas de anelamento dos ramos, antes da retirada dos garfos, utilizando-se da enxertia por garfagem tipo inglês simples.

\section{MATERIAL E MÉTODOS}

O experimento foi realizado sob condições de ripado, na Faculdade de Ciências Agrárias e Veterinárias - UNESP, Câmpus de Jaboticabal, município localizado a $21^{\circ} 15^{\prime} 22^{\prime \prime}$ Sul e $48^{\circ} 8^{\prime} 58^{\prime \prime}$ Oeste, com altitude de $595 \mathrm{~m}$, possuindo clima subtropical-úmido com estiagem de inverno.

Os alporques (que originariam parte dos porta-enxertos) foram realizados selecionando-se ramos firmes, conforme recomenda Garner (1976), com comprimento aproximado de 40 $\mathrm{cm}$ entre a parte terminal e o local de anelamento, cuja largura era de aproximadamente $2 \mathrm{~cm}$, utilizando esfagno como substrato. $\mathrm{O}$ porta-enxerto utilizado no experimento tinha cerca de 1 ano, foi obtido por sementes e conduzido em ripado.

Os garfos para a enxertia (para ambos os tipos de portaenxertos) foram obtidos das duas árvores-matrizes que originaram os alporques, tendo sido executados os anelamentos nos ramos que viriam a ser coletados como garfos anelados. $\mathrm{O}$ sistema utilizado foi o de garfagem tipo inglês simples.

Os tratamentos consistiam no uso de três sistemas de anelamento do ramo doador do garfo, e dois tipos de portaenxerto. $\mathrm{O}$ experimento foi instalado de acordo com o esquema fatorial $2 \mathrm{X} 3 \mathrm{com}$ os fatores porta-enxerto (alporque e pé-franco) e anelamento (sem anelamento, anelamento de duas semanas, anelamento de quatro semanas), em delineamento inteiramente

1 (Trabalho 224/2000). Recebido: 09/10/2000. Aceito para publicação: 08/02/2002.

2 Eng ${ }^{\circ}$. Agrônomo, DSc., Prof. do Dept ${ }^{\circ}$ de Produção Vegetal da FCAV/UNESP - Campus de Jaboticabal. E-mail: baldo@fcav.unesp.br

3 Eng $^{\circ}$ Agrônomo. Dept ${ }^{\circ}$ de Produção Vegetal da FCAV/UNESP - Campus de Jaboticabal

4 Enga . Agrônoma, MSc., Doutoranda em Agronomia: Produção Vegetal - FCAV/UNESP - Campus de Jaboticabal. FCAV/UNESP. Depto. de Produção Vegetal. Rodovia Prof. Paulo Donato Castellane, Km 5. CEP. 14870.000 Jaboticabal - SP. E-mail: veruska@fcav.unesp.br 
casualizado, com três repetições, totalizando 18 parcelas, com oito plantas cada. A porcentagem de pegamento do enxerto foi avaliada aos 30 e 45 dias.

\section{RESULTADOS E DISCUSSÃO}

Após o período de 30 dias da operação de enxertia, determinou-se a porcentagem de pegamento e verificou-se a sobrevivência dos enxertos (Tabela 1). Verifica-se que houve diferenças no pegamento do enxerto, tanto em função do tipo de porta-enxerto usado quanto devido ao anelamento do ramo doador do garfo, além de mostrar uma interação de efeitos entre os dois fatores estudados (porta-enxerto $\mathrm{x}$ anelamento). $\mathrm{O}$ teste de Tukey para as médias do fator tipo de porta-enxerto mostra que houve diferença significativa entre os dois tipos de portaenxerto. Para as médias do fator época de anelamento, observase que o anelamento de duas semanas foi mais propício para o pegamento que o de quatro semanas, embora não tenha sido detectada diferença nos ramos que não foram anelados. Contudo, quando se usa porta-enxerto proveniente de alporque, o resultado é quase nulo; por sua vez, com a enxertia em cavalos originados de sementes, obteve-se uma porcentagem de sucesso de cerca de $27,2 \%$, número bastante baixo, mas significativamente maior que $\mathrm{o}$ anterior $(0,5 \%)$.

Vários fatores provavelmente influenciaram na superioridade dos tratamentos com porta-enxerto tipo pé-franco, sendo que o vigor pode ser considerado como o mais importante. Venturieri et al. (1987) e Fachinello et al. (1995) mencionam a técnica de garfagem em fenda simples como um dos métodos de enxertia com melhores resultados, apesar de possuir o inconveniente de o enxerto danificar-se muito facilmente, justamente pela fragilidade do contato das duas partes, o que pode ter sido responsável pelos baixos índices obtidos no presente trabalho.

Com relação aos porta-enxertos provenientes de alporquia, pode-se citar o desfolhamento parcial como uma das possíveis causas da menor porcentagem de pegamento, uma vez que a muda perdia quase a totalidade de suas folhas ao ter o ápice podado para a enxertia, região na qual se acumulava o maior número de folhas do alporque. No entanto, os pés-francos continham mais folhas na região basal do caule, o que pode ter estimulado o pegamento. Essas respostas assemelham-se com as encontradas por Venturieri et al.(1987) e Sharma et al. (1990). Em cupuaçuzeiro, Venturieri et al. (1987) concluíram que o desfolhamento parcial diminuiu o pegamento dos enxertos. Sharma et al. (1990) também obtiveram os piores resultados na sobrevivência de alporques de lichia com $100 \%$ de desfolha. O mesmo não se verifica, entretanto, nos estudos de Sharfuddin (1983), que constatou maior sobrevivência em alporques de lichia quando tratadas com desfolha intensa.

No estudo do anelamento, duas semanas antes da enxertia, observa-se o maior pegamento quando comparado ao de quatro semanas (Tabela 1). $\mathrm{O}$ anelamento contrariou as expectativas, visto que, nos estudos de Ojima et al. (1984) com nogueira-macadâmia, o melhor tratamento foi o do anelamento de quatro a oito semanas antes da enxertia, com porcentagem de pegamento praticamente duas vezes maior em relação aos ramos não anelados. Este foi um resultado relevante, pois Villalobos e Peraza (1986) salientam que, de um modo geral, o anelamento em frutíferas deve ser de seis a oito semanas.

Após 15 dias da primeira avaliação (45 dias após a enxertia), foi realizada uma segunda coleta de dados, na qual se verificou a morte de alguns enxertos (Tabela 2).

Em relação à sobrevivência de mudas e enxertos, é natural a ocorrência de morte em uma pequena porcentagem de alporques, pois as novas raízes podem não estar adaptadas ao novo ambiente no devido tempo (Oosthuizen, 1992).

Outro aspecto importante a considerar é a propriedade que muitas plantas frutíferas possuem de eliminar substâncias tóxicas ao tecido por ocasião do corte, o que acarreta dificuldades para a formação do calo, além de a própria fragilidade do contato entre as partes enxertadas influenciar na manutenção do enxerto (Fachinello et al., 1995).

A idade dos porta-enxertos também é um fator de relevância na sobrevivência dos enxertos, uma vez que foram utilizados pés-francos com mais de hum ano e alporques com seis meses. Os melhores resultados foram provenientes de portaenxertos de pés-franco. Esses resultados contrastam com os resultados obtidos por Sampaio e Barbin (1980) e Dall'orto et al. (1988), em cultura da nogueira-macadâmia, os porta-enxertos com mais de uma ano de idade tiveram eficiência de pegamento inferior

TABELA 1 - Análise de variância e resultados do teste de Tukey para porcentagem de pegamento dos enxertos, 30 dias após a enxertia.

\begin{tabular}{lcc}
\hline Causas de variação & GL & Quadrados médios \\
\hline Tipo de porta-enxerto(A) & 1 & $3292,07^{* * *}$ \\
Época de anelamento(B) & 2 & $369,69^{* *}$ \\
Interação A x B & 2 & $801,09^{* *}$ \\
Resíduo & 12 & 51,41 \\
\hline C.V.(\%) & 23,94 \\
\hline \multicolumn{2}{l}{} \\
\hline Porta-enxerto poralporque & $16,43 \mathrm{~B}$ \\
Porta-enxerto pé-franco & Médias de Tukey & $43,48^{\mathrm{A}}$ \\
\hline Sem anelamento & & $29,59 \mathrm{AB}$ \\
Anelamento c/2 semanas & $37,97^{\mathrm{A}}$ \\
Anelamento c/4 semanas & $22,29 \mathrm{~B}$ \\
\hline
\end{tabular}

1/ Valores transformados em arc-sen $\sqrt{\mathrm{x}+0,5}$

** $\mathrm{P}<0,01$

Médias seguidas de mesma letra não diferem entre si, pelo teste de Tukey $(\mathrm{P}>0,05)$. 
TABELA 2 - Análise de Variância e resultados do teste de Tukey para porcentagem de pegamento dos enxertos, 45 dias após a enxertia.

\begin{tabular}{llc}
\hline Causas de variação & G & Q.médios \\
\hline Tipo de porta-enxerto(A) & 1 & $3376,98^{*}$ \\
Época de anelamento(B) & 2 & $40,24^{\mathrm{ns}}$ \\
Interação A x B & 2 & $40,24^{\mathrm{ns}}$ \\
Resíduo & 12 & 57,82 \\
\hline C.V.(\%) & 42,83 \\
\hline & Médias de Tukey \\
\hline Porta-enxerto por alporque & $4,05 \mathrm{~B}$ \\
Porta-enxerto pé-franco & & $31,45 \mathrm{~A}$ \\
\hline
\end{tabular}

1/ Valores transformados em arc-sen $\sqrt{\mathrm{x}+0,5}$

ns - Não significativo

** $\mathrm{P}<0,01$

Médias seguidas de mesma letra não diferem entre si, pelo teste de Tukey $(\mathrm{P}>0,05)$.

em relação aos porta-enxertos de seis meses de idade.

No presente trabalho, observou-se a importância da permanência de cobertura plástica sobre os garfos por um período superior a 60 dias, devido à união das partes ser muito lenta nesta espécie, retardando a conexão dos vasos e a conseqüente translocação de água e nutrientes requeridos pela brotação incipiente das gemas. Essas observações são coincidentes com as de Ojima et al.(1984) em nogueira-macadâmia, na qual a proteção dos garfos nos primeiros 30 a 40 dias foi fundamental. Entretabto, Garner (1976), sugere que, para permitir a expansão do broto sem prováveis danos, ao invés da retirada do plástico, se execute um corte no próprio plástico, na altura da gema em brotação.

\section{CONCLUSÃO}

O tratamento que proporcionou melhores resultados aos 30 dias, foi a enxertia com ramos anelados duas semanas antes em porta-enxerto tipo pé-franco. Os resultados menos expressivos foram obtidos quando se utilizou garfos com quatro semanas de anelamento enxertados em porta-enxertos provenientes de alporquia.

Em relação à sobrevivência das gemas do enxerto, 45 dias após a enxertia, verificou-se que a alta porcentagem de mortalidade deve-se, provavelmente, ao fator porta-enxerto tipo alporque, pois diferiu significativamente dos fatores anelamento e porta-enxerto tipo pé-franco.

\section{REFERÊNCIAS BIBLIOGRÁFICAS}

DALL'ORTO, F. A. C. et al. Nogueira-macadâmia - Enxertia precoce. Casa da Agricultura, Campinas, n.3, p.20-21, 1988.
FACHINELLO, J. C. et al. Propagação de plantas frutíferas de clima temperado. 2. ed. Pelotas : Editora UFPEL,1995.179p.

GARNER, R. J. Propagation of tropical fruit trees. 1. ed. Slough :Farnham Royal, 1976. 566p.

OJIMA, M. et al. Resultados experimentais de propagação da nogueira-macadâmia no Instituto Agrícola de Campinas. In: VII CONGRESSO BRASILEIRO DE FRUTICULTURA, EMPASC, SBF, Anais: Florianópolis, SC. v.4, p.1038-1053, 1984.

OOSTHUIZEN, J. H. Propagation methods - Cultivation practices. In: OOSTHUIZEN, J. H. et al. The cultivation of litchis. Agricultural Research Council, 1992, p.19-22.

SAMPAIO, V. R., BARBIN, D. Competição entre enxertias de mesa de canteiro em nogueira-pecã. Anais da ESALQ, Piracicaba, v.37, n.2, p.329-334, 1980.

SHARFUDDIN, A. F. M. Effect of pruning of the survival of detached rooted air layers in litchi. Bangladesh Horticulture, v.11, n.1, p.39-40, 1983.

SHARMA, S. B. , RAY, P. K. , SINGH, B. K. A note on the effect of defoliation no survival of litchi layers in nursery. Haryana Journal of Horticultural Science, v. 19, n.1-2, p.129-130, 1990.

VENTURIERI, G. A. , MARTEL, J. H. I., MACHADO, G. M. E. Enxertia do cupuaçuzeiro ( Theobroma grandiflorum Schum.) com uso de gemas e garfos com e sem toalete. Acta Amazônica, n.16/17, p.27-40, 1987.

VILLALOBOS, O. G. , PERAZA, R. C. Macadamia-tecnicas para su produccion. 1. ed. San José : Universidad de Costa Rica, 1986. $35 \mathrm{p}$. 